\title{
TITLE:
}

\section{Thermal Quenching Mechanism of CaAlSiN:Eu² Red Phosphor}

$\operatorname{AUTHOR}(\mathrm{S})$ :

Ueda, Jumpei; Tanabe, Setsuhisa; Takahashi, Kohsei; Takeda, Takashi; Hirosaki, Naoto

\section{CITATION:}

Ueda, Jumpei ...[et al]. Thermal Quenching Mechanism of CaAlSiN:Eu² Red Phosphor. Bulletin of the Chemical Society of Japan 2018, 91(2): 173-177

\section{ISSUE DATE:}

2018-02-15

URL:

http://hdl.handle.net/2433/233791

\section{RIGHT:}

(C) 2018 The Chemical Society of Japan; 発行元の許可を得て登録してい ます:; This is not the published version. Please cite only the published version.; この論文は出版社版でありません。引用の際には出版社版を ご確認ご利用ください。 


\title{
Thermal Quenching Mechanism of CaAlSiN ${ }_{3}: \mathrm{Eu}^{2+}$ Red Phosphor
}

\author{
Jmpei Ueda, ${ }^{* 1}$ Setsuhisa Tanabe, ${ }^{1}$ Kohsei Takahashi, ${ }^{2}$ Takashi Takeda, ${ }^{2}$ Naoto Hirosaki ${ }^{2}$ \\ ${ }^{1}$ Graduate School of Human and Environmental Studies, Kyoto University, Yoshida-nihonmatsu-cho, Sakyo-ku, Kyoto 606-8501
}

${ }^{2}$ Sialon Group, National Institute for Materials Science, 1-1 Namiki, Tsukuba 305-0044

E-mail: ueda.jumpei.5r@kyoto-u.ac.jp

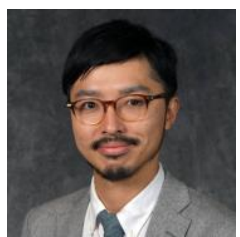

\section{Jumpei Ueda}

Jumpei Ueda received Ph.D degree from Kyoto University in 2012 under the supervision of Professor Setsuhisa Tanabe. In 2012, he became an assistant professor in Graduate School of Human and Environmental Studies, Kyoto University.

\begin{abstract}
$\mathrm{CaAlSiN}_{3}: \mathrm{Eu}^{2+}$ is a widely applied phosphor in white LEDs (w-LEDs) because of strong blue absorption and efficient red luminescence. The good stability against thermal quenching has been well established, but the mechanism for the luminescence quenching at high temperatures has not been elucidated yet. In this report, we investigate the possibility of thermal ionization quenching by thermoluminescence (TL) and persistent luminescence techniques. In the TL glow curve by UV charging at $100 \mathrm{~K}$, two broad TL glow bands were observed around 160 and $390 \mathrm{~K}$. The higher TL glow band was not observed by $550 \mathrm{~nm}$ charging at $300 \mathrm{~K}$, but it was observed by charging at $400 \mathrm{~K}$, which corresponds to the onset temperature of luminescence quenching. Because the $550 \mathrm{~nm}$ light excites the lowest $5 d$ level of $\mathrm{Eu}^{2+}$, we conclude that the luminescence quenching of $\mathrm{CaAlSiN}_{3}: \mathrm{Eu}^{2+}$ at high temperatures is caused by the thermal ionization.
\end{abstract}

\section{Introduction}

White LEDs (Light Emitting Diodes) illumination are rapidly replacing incandescent lamps and (compact) fluorescent tubes in the indoor lighting markets. This revolution in indoor lighting has been enabled not only by the invention of the blue $\mathrm{LED}^{1}$, but also by the development of visible phosphors. The conventional white LED (w-LED) is a phosphor converted white-LED, which is composed of an InGaN-based blue LED and visible light emitting inorganic phosphors. From the dawn of the w-LED development, the w-LEDs usually use the $\mathrm{Y}_{3} \mathrm{Al}_{5} \mathrm{O}_{12}: \mathrm{Ce}^{3+}$ yellow phosphor ${ }^{2,3}$, but it does not show high color rendering due to the lack of red luminescent component. In 2006, Uheda, Hirosaki and Yamamoto developed a new red phosphor of $\mathrm{CaAlSiN}_{3}: \mathrm{Eu}^{2+}$, which has strong absorption at blue LED wavelength, high quantum efficiency and excellent thermal quenching behavior. ${ }^{4,5}$ Since this discovery, the CaAlSiN $3: \mathrm{Eu}^{2+}$ phosphor has become one of the typical red phosphors for warm w-LEDs although many alternative phosphors have been designed. ${ }^{6}$

Especially, such an excellent thermal quenching behavior is important for the w-LED phosphors because the temperature of the LED chip reaches up to $\sim 200^{\circ} \mathrm{C}$ in recent high power wLED applications. However, even the $\mathrm{CaAlSiN}_{3}: \mathrm{Eu}^{2+}$ phosphor still shows thermal quenching at higher temperatures above $400 \mathrm{~K}^{7}$. For this thermal quenching mechanism, two possibilities have been considered. One is the thermally activated crossover from the $5 d$ level to the $4 f$ levels ${ }^{7-9}$, the other is the thermal ionization from the $5 d$ excited level to the bottom of the conduction band (CB). ${ }^{10,11}$ Zhang and Hintzen et al. investigated the energy gap between the lowest $5 d$ level of $\mathrm{Eu}^{2+}$ and $\mathrm{Yb}^{2+}$ and the bottom of $\mathrm{CB}\left(\Delta E_{5 d-\mathrm{CB}}\right)$ and found the correlation between thermal quenching behavior and $\Delta E_{5}$-СB. ${ }^{12}$ Thus, they proposed the thermal ionization quenching in $\mathrm{CaAlSiN}_{3}: \mathrm{Eu}^{2+}$ as well as $\mathrm{CaAlSiN}_{3}: \mathrm{Yb}^{2+}$. Also, because the thermal ionization quenching was predicted and proved in other $\mathrm{Eu}^{2+}$ phosphors by the investigation of energy diagram ${ }^{13-15}$ and photoconductivity ${ }^{16,17}$, the thermal ionization process may be the most probable path in the $\mathrm{CaAlSiN}_{3}: \mathrm{Eu}^{2+}$ phosphor.

In this study, the possibility of the thermal ionization process was investigated using thermoluminescence (TL) and persistent luminescence (PersL) spectroscopy. In general, TL as well as PersL is caused by detrapping of electrons, that were previously trapped, and by the recombination with hole-trapped luminescence center. Electron charging occurs when electrons in the excited state of luminescence centers are transferred to the CB (e.g., through thermal ionization) and then captured by traps in the host. Thus, the TL and PersL intensity depend on the thermal ionization efficiency in the non-saturation condition of electron traps. Recently, we successfully demonstrated the thermal ionization quenching of the most widely uesed $\mathrm{Y}_{3} \mathrm{Al}_{5} \mathrm{O}_{12}: \mathrm{Ce}^{3+}$ yellow phosphors by observation of the charging process from the lowest $5 d$ level to the $\mathrm{CB}$ at high temperatures in the TL excitation specturm ${ }^{18}$. For the $\mathrm{CaAlSiN}_{3}: \mathrm{Eu}^{2+}$, a broad TL glow band in the range between 300 to $673 \mathrm{~K}$ was reported $^{19}$. Therefore, the investigation of thermal ionization quenching by TL and PersL measurements can be applied for the $\mathrm{CaAlSiN}_{3}: \mathrm{Eu}^{2+}$ phosphor.

\section{Experimental}

$\mathrm{CaAlSiN}_{3}: \mathrm{Eu}^{2+}(1 \%)$ phosphor was prepared by the solidstate reaction at $1800{ }^{\circ} \mathrm{C}$ under $\mathrm{N}_{2}$ gas of 10 atm. A crystalline phase was identified as a single phase of $\mathrm{CaAlSiN}_{3}$ crystal. Temperature dependence of PL spectra was measured by a multichannel CCD spectrometer (QE65PRO, Ocean Optics,) and a cryostat (Helitran LT3, Advanced Research Systems). A combination of a 300-W Xe lamp (MAX-302, Asahi Spectra Co. Ltd) and a bandpass filter (460 nm) was used as the excitation source. TL glow curves were obtained using the cryostat and a photomultiplier tube (R3896, Hamamatsu Photonics, Hamamatsu). For the excitation source for the TL glow curve measurement, the Xe lamp with a UV cold mirror and with a 550 $\mathrm{nm}$ bandpass filter was used.

Photoluminescence excitation (PLE) and persistent luminescence excitation (PersLE) spectra were measured using a fluorescence spectrophotometer (RF-5000, Shimadzu). In 
the persistent luminescence excitation measurement, the sample was charged by the monochromatic light for $1 \mathrm{~min}$, and then a persistent spectrum was measured 1 min after ceasing excitation. The charging wavelength was changed by $10 \mathrm{~nm}$ intervals from 680 to $200 \mathrm{~nm}$.

\section{Results and Discussion}

Figure 1 shows PL spectra of the $\mathrm{CaAlSiN}_{3}: \mathrm{Eu}^{2+}$ sample at different temperatures from 85 to $785 \mathrm{~K}$. At all temperatures, a red luminescence band due to $\mathrm{Eu}^{2+}: 5 d-4 f$ was observed. With increasing temperature, the peak wavelength of PL band is shifted to shorter wavelength and the FWHM (full width at half maximum) becomes wider. This is because the $\mathrm{Eu}^{2+}$ ions with $5 d$ excited state obey the Boltzmann distribution and the population of $\mathrm{Eu}^{2+}$ with higher $5 d$ excited state coupled with several phonons increases with increasing temperature.

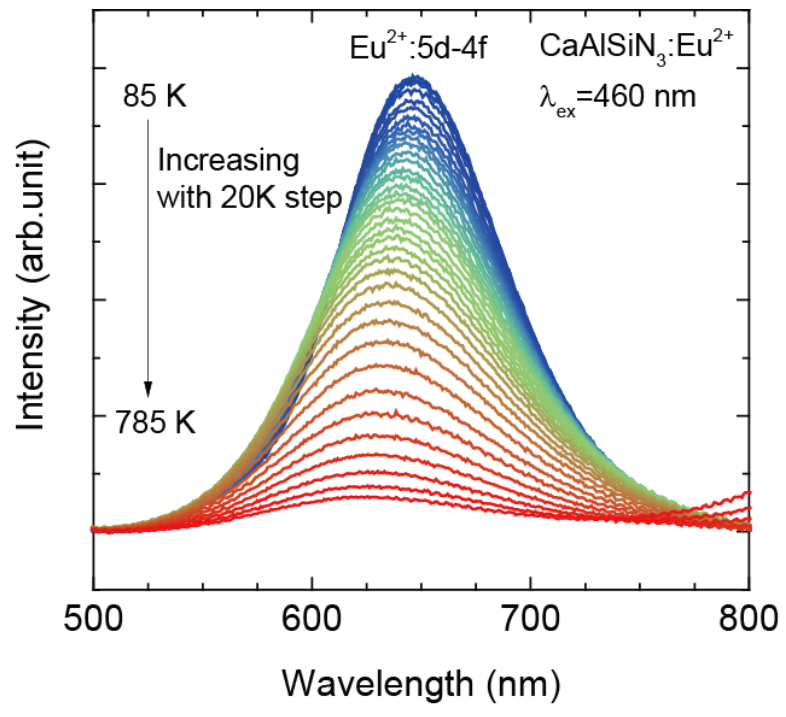

Figure 1. PL spectra of $\mathrm{CaAlSiN}_{3}: \mathrm{Eu}^{2+}$ by $460 \mathrm{~nm}$ excitation at different temperatures.

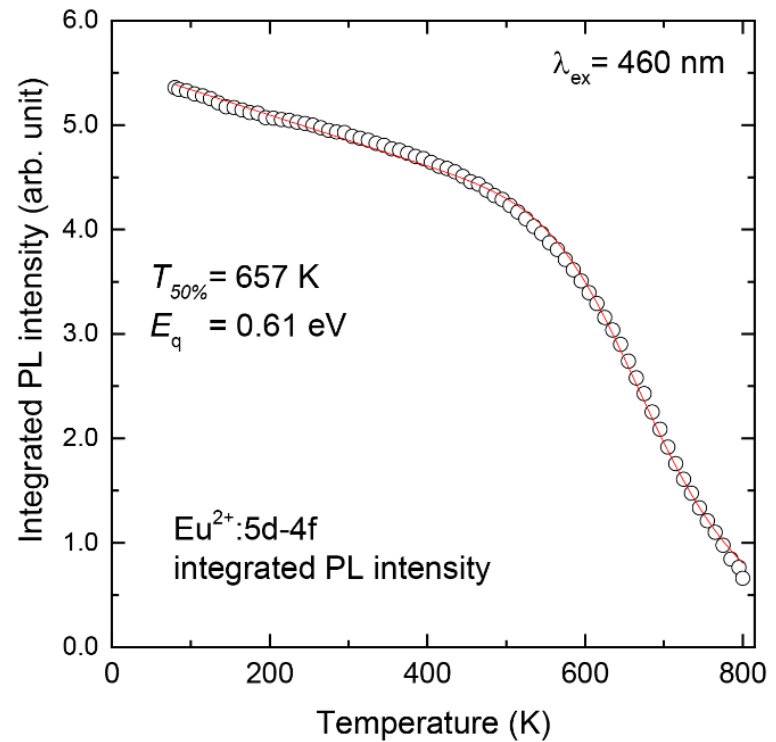

Figure 2. Temperature dependence of $\mathrm{Eu}^{2+}: 5 d-4 f \mathrm{PL}$ intensity.

The temperature dependence of integrated PL intensity is shown in Figure 2. The PL intensity slightly decreases with a gentle slope up to $400 \mathrm{~K}$ and the slope changes to be steeper. The initial decrease of photoluminescence intensity can be caused by the temperature dependence of absorption coefficient at $460 \mathrm{~nm}$. Assuming linear decreasing dependence of absorption coefficient with increasing temperature, the temperature dependence of PL intensity can be fitted below equation,

$$
I(T)=\left(I_{0}-a \times T\right) /\left(1+\Gamma_{0} / \Gamma_{v} \exp \left(-E_{q} / k T\right)\right)(1) .
$$

Where, $I(T)$ is the PL intensity at a given point in temperatures, $I_{0}$ is the intensity at $0 \mathrm{~K}, \Gamma_{v}$ is the radiative rate, $\Gamma_{0}$ is the attempt rate of the nonradiative process, $E_{q}$ is the activation energy for nonradiative process, $k$ is the Boltzmann constant, $T$ is the temperature and $a$ is the factor of proportionality for temperature dependence of absorption coefficient. From the fitting result, the activation energy for main quenching process was estimated to be $0.61 \mathrm{eV}$, and $\Gamma_{0} / \Gamma_{v}$ was $2.6 \times 10^{4}$. To elucidate the main temperature quenching above $400 \mathrm{~K}$, we tried to investigate the possibility of thermal ionization quenching by the thermoluminescence technique.

Figure 3 shows the luminescence decay curve of $5 d-4 f$ luminescence in the $\mathrm{CaAlSiN}_{3}: \mathrm{Eu}^{2+}$ sample. Typical fluorescence decay curve of the $\mathrm{Eu}^{2+}: 5 d-4 f$ transition was observed. The decay curve was fitted by below equation,

$$
I(t)=I_{0} \times \exp (-t / \tau)
$$

Here, $I(t)$ is the PL intensity at a given point in time $(t), I_{0}$ is the initial intensity, $\tau$ is the lifetime. From the fitting result, the lifetime was estimated to be $801 \mathrm{~ns}$. Because the thermal quenching is not caused at room temperature, the non-radiative rate is roughly regarded as 0 . Thus, the radiative rate can be calculated to be approximately $1.3 \times 10^{6} \mathrm{~s}^{-1}$ from the reciprocal of the lifetime.

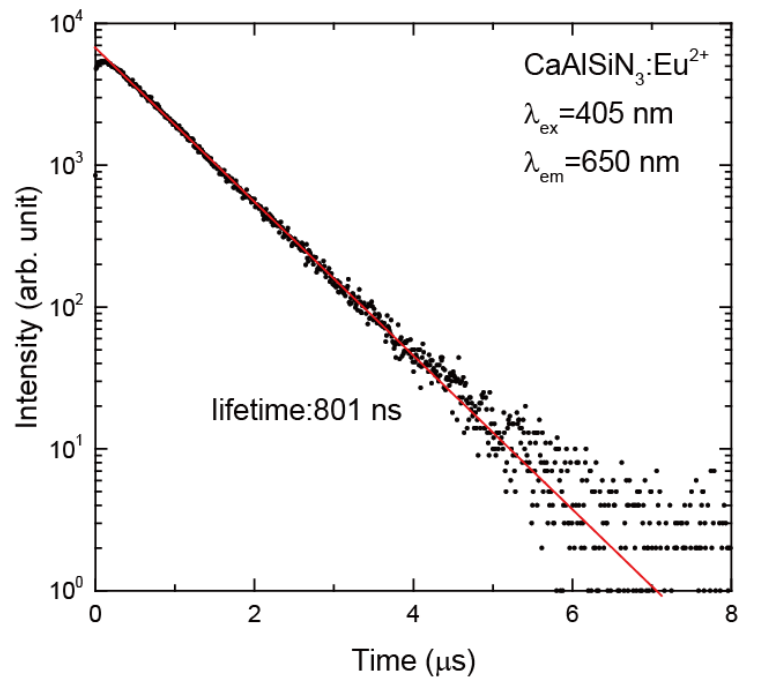

Figure 3. Fluorescence decay curve of $\mathrm{CaAlSiN}_{3}: \mathrm{Eu}^{2+}$.

Figure $4 \mathrm{a}$ shows the TL glow curves after UV charging at $80 \mathrm{~K}$ and $300 \mathrm{~K}$ and after $550 \mathrm{~nm}$ charging at $300 \mathrm{~K}$. From the TL glow curve by UV charging at $80 \mathrm{~K}$, two main TL glow bands were observed at 163 and $392 \mathrm{~K}$. These two TL glow bands correspond to shallow and deep traps, which can be originated from some intrinsic or extrinsic defects. The most probable electron trap can be oxygen impurity in the $\mathrm{N}^{3-}$ site $\left(\mathrm{O}_{\mathrm{N}}\right)^{19}$. Because the present sample shows a high TL glow band above $400 \mathrm{~K}$ which is the onset temperature of main thermal quenching, the quenching process by thermal ionization from the lowest $5 d$ energy level to $\mathrm{CB}$ can be evaluated by the measurement of TL glow curves. In Figure 4a, the TL glow peak at around $392 \mathrm{~K}$ was also observed after UV charging at $300 \mathrm{~K}$, but not observed after $550 \mathrm{~nm}$ excitation at $300 \mathrm{~K}$. The $550 \mathrm{~nm}$ wavelength corresponds to the transition wavelength from the $4 f$ ground to the lowest $5 d$ level of $\mathrm{Eu}^{2+}$ in the CaAlSiN 3 host. Thus, the thermal ionization process from the lowest $5 d$ level to the 
conduction band does not occur at $300 \mathrm{~K}$. The thermal energy at $300 \mathrm{~K}$ is not large enough to overcome the energy barrier from the lowest $5 d$ level to the CB. On the other hand, when the charging temperature increases from $300 \mathrm{~K}$ to $500 \mathrm{~K}$ by $50 \mathrm{~K}$ each, TL glow bands start to appear in the range between $400 \mathrm{~K}$ and $600 \mathrm{~K}$ even by $550 \mathrm{~nm}$ excitation as shown in Figure $4 \mathrm{~b}$. The observation of TL glow peak at higher charging temperatures shows that the charging process from the lowest $5 d$ level to the CB is caused by the thermally activated process.

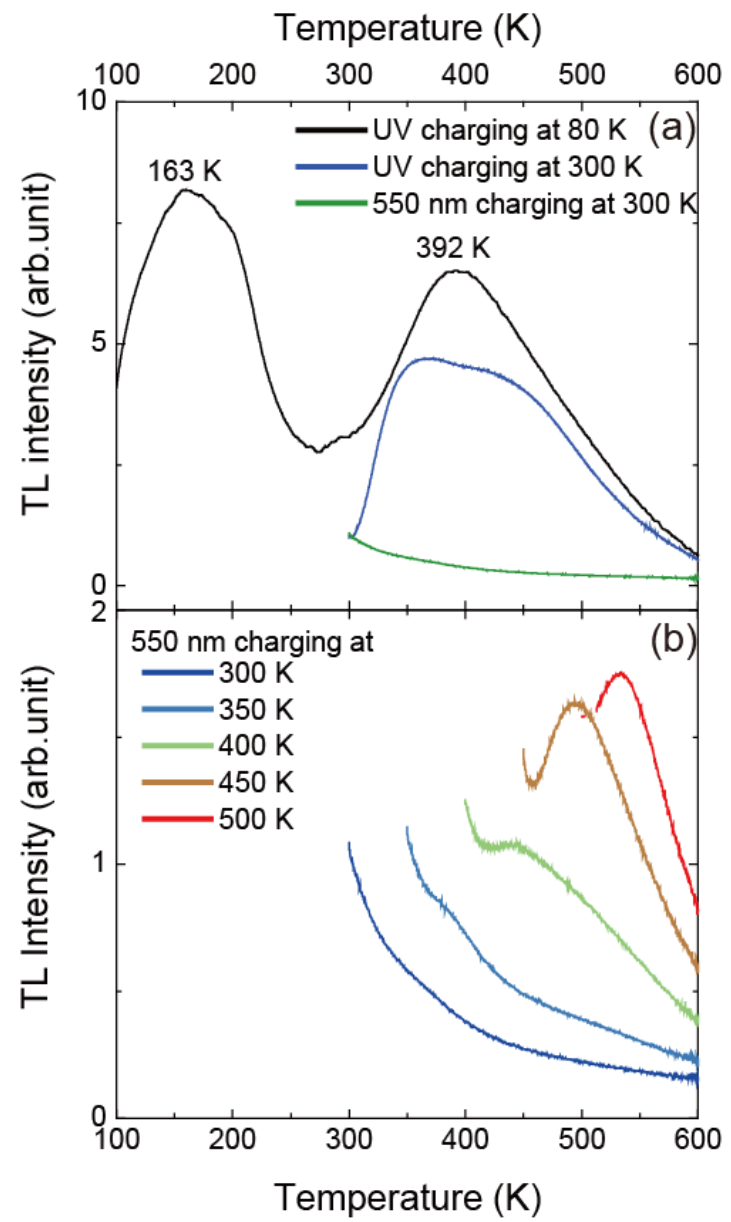

Figure 4. TL glow curves (a) by UV charging at $80 \mathrm{~K}$ and $300 \mathrm{~K}$ and by $550 \mathrm{~nm}$ charging at $300 \mathrm{~K}$ and (b) by $550 \mathrm{~nm}$ charging at different temperatures.

In order to check the possibility of thermal ionization process from the lowest $5 d$ levels in detail, the persistent luminescence excitation spectra were measured at $300 \mathrm{~K}$ and 450 $\mathrm{K}$. Figure $5 \mathrm{~b}$ and $5 \mathrm{c}$ show that the contour plots of persistent luminescence intensity versus charging wavelength and emission wavelength at $450 \mathrm{~K}$ and $300 \mathrm{~K}$, respectively. The $\mathrm{CaAlSiN}_{3}: \mathrm{Eu}^{2+}$ sample exhibited red persistent luminescence at $300 \mathrm{~K}$ and $450 \mathrm{~K}$ after UV excitation. The generation of persistent luminescence can be understood from the broad TL glow curves in the range between 300 and $600 \mathrm{~K}$ as shown in Figure 4a. In the contour plot of PersL intensity at $300 \mathrm{~K}$, the red persistent luminescence band was observed only after UV excitation from $250 \mathrm{~nm}$ to $350 \mathrm{~nm}$, but not after visible excitation. On the other hand, in the contour plot at $450 \mathrm{~K}$, a PersLE band from $350 \mathrm{~nm}$ to $650 \mathrm{~nm}$ was observed in addition to the UV PersLE band. From the PLE spectrum of $700 \mathrm{~nm}$ in $\mathrm{CaAlSiN}_{3}: \mathrm{Eu}^{2+}$ as shown in Figure 5a, the lowest $5 d$ excitation band spreads from 500 to $650 \mathrm{~nm}$. In the same range, the
PersLE band was also observed only in PersLE spectrum at 450 $\mathrm{K}$, but not at $300 \mathrm{~K}$. Based on these results, we conclude that the thermal quenching of $\mathrm{CaAlN}_{3}: \mathrm{Eu}^{2+}$ luminescence is caused by thermal ionization process, not by internal crossing quenching from $5 d$ level to $4 f$ level.
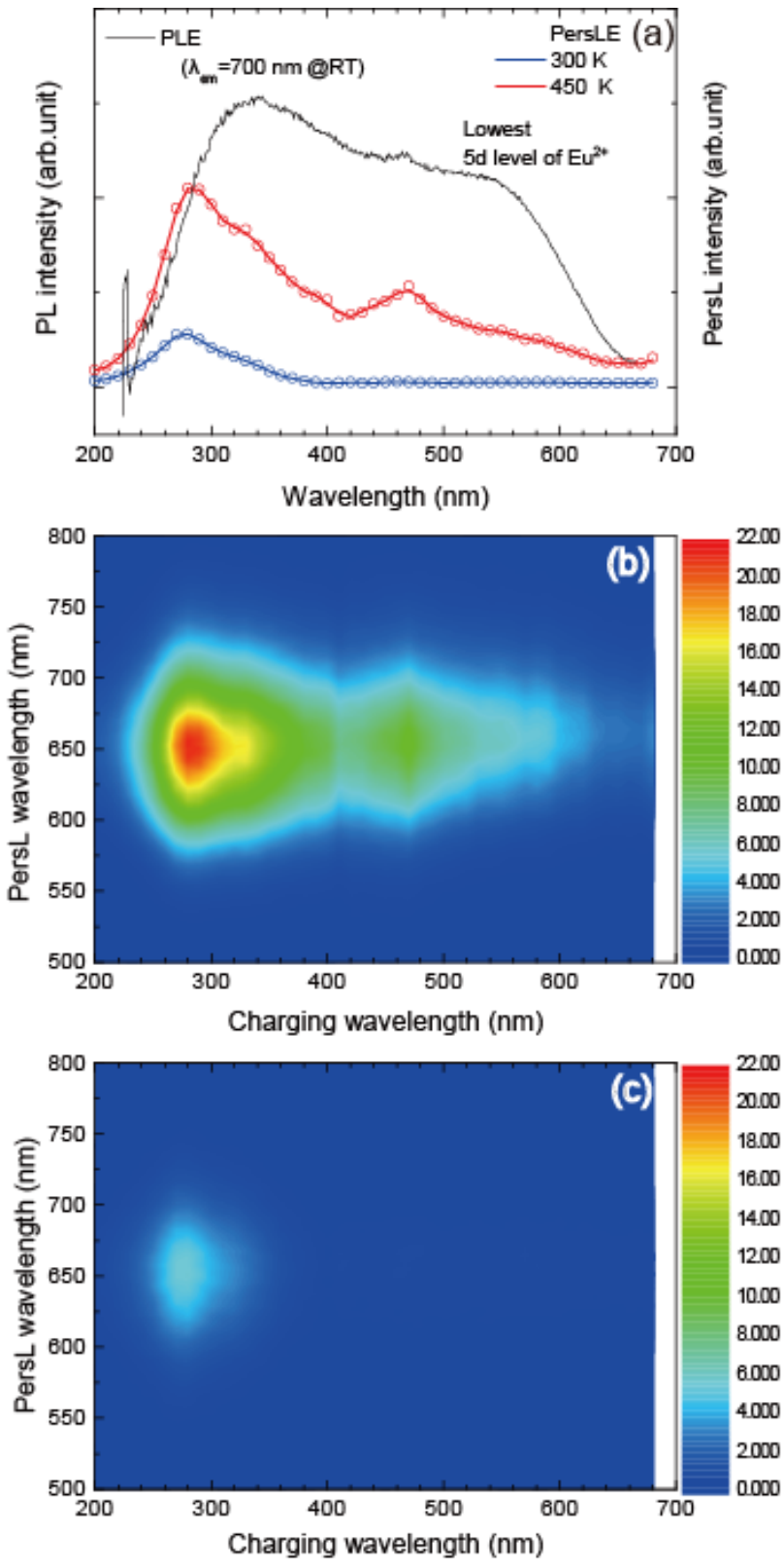

Figure 5. (a) Comparison of PLE and PersLE at $300 \mathrm{~K}$ and

450K. Contour plot of PersL intensity versus charging

wavelength and PersL wavelength at (b) $450 \mathrm{~K}$ and (c) $300 \mathrm{~K}$.

This thermal ionization quenching is also understood from the vacuum referred binding energy (VRBE) diagram as shown in Figure 6. Lanthanide-host referred binding energy (HRBE) diagram in $\mathrm{CaAlSiN}_{3}$ host was reported by Zhang, and Hintzen et al. $^{20}$ and the VRBE of $\mathrm{Eu}^{2+}$ was reported by Dorenbos ${ }^{21}$. Using these reported parameter such as host exciton energy ( $E^{\text {ex }}$ $=4.9 \mathrm{eV}$ ) at room temperature, charge transfer energy of $\mathrm{Sm}^{3+}$ $\left(E^{\mathrm{CT}}{ }_{\mathrm{Sm} 3+}=3.91 \mathrm{eV}\right), \quad \mathrm{VRBE}$ of $\mathrm{Eu}^{2+}$ in $\mathrm{CaAlSiN}_{3}$ $\left(E_{4 f}\left(7,2+, \mathrm{CaAlSiN}_{3}\right)=-3.71 \mathrm{eV}\right)$, the VRBE diagram was constructed as shown in Figure 6. Here, we assumed that the host exciton energy shifts to higher energy by approximately $0.15 \mathrm{eV}$ from $300 \mathrm{~K}$ to $10 \mathrm{~K}$. Also, to correct the electron and hole 
binding energy, the host exciton energy at low temperature was multiplied by $1.08 .^{22}$ As a result, the band gap was estimated to be $5.5 \mathrm{eV}$. From the VRBE diagram, the energy gap between $5 d$ energy level and the bottom of $\mathrm{CB}\left(\Delta E_{5 \mathrm{~d}-\mathrm{CB}}\right)$ is estimated to be $0.65 \mathrm{eV}$. The excited electron at the $5 d$ level can be jumped to $\mathrm{CB}$ at higher temperatures because of this moderate energy gap between these. The VRBE diagram also supports the thermal ionization quenching in $\mathrm{CaAlSiN}_{3}: \mathrm{Eu}^{2+}$.

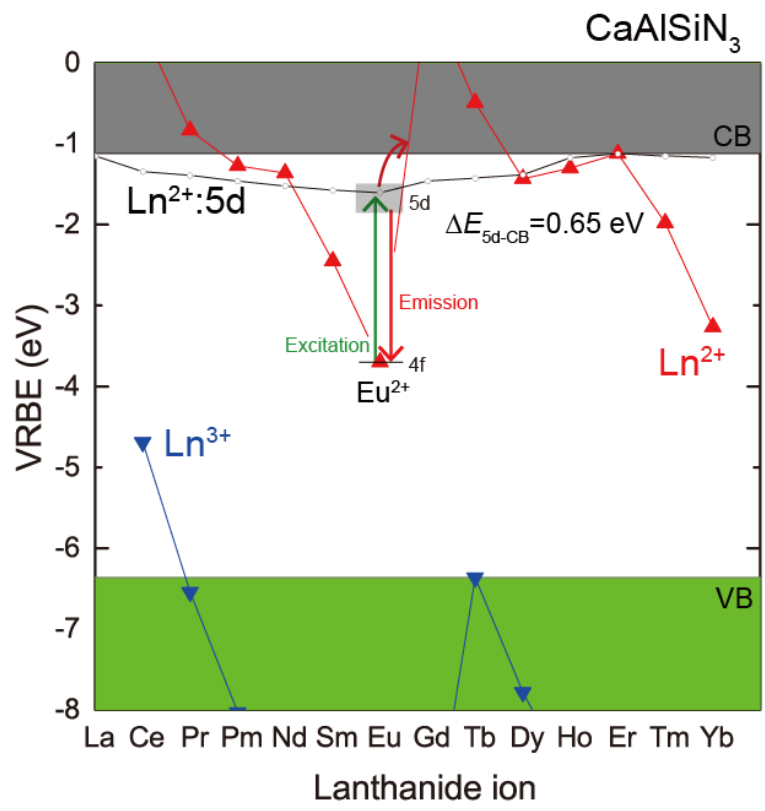

Figure 6. VRBE diagram of $\mathrm{CaAlSiN}_{3}$.

\section{Conclusion}

The photoluminescence spectra of $\mathrm{CaAlSiN}_{3}: \mathrm{Eu}^{2+}$ was measured at various temperatures from $80 \mathrm{~K}$ to $800 \mathrm{~K}$. The PL intensity decreases with increasing temperature. In order to investigate the possibility of thermal ionization quenching, thermoluminescence (TL) and persistent luminescence excitation spectra were measured. In the TL glow curve by UV charging at $100 \mathrm{~K}$, two broad TL glow bands were observed around 160 and $390 \mathrm{~K}$. The higher TL glow band was not observed by $550 \mathrm{~nm}$ charging at $300 \mathrm{~K}$, but it was observed by $550 \mathrm{~nm}$ charging at $400 \mathrm{~K}$ which corresponds to the onset temperature of luminescence quenching. Because the $550 \mathrm{~nm}$ light excites the lowest $5 d$ level of $\mathrm{Eu}^{2+}$, the charging process from the lowest $5 d$ level is caused at high temperatures. In addition, the lowest $5 d$ band of $\mathrm{Eu}^{2+}$ was observed in the persistent luminescence excitation spectrum at $450 \mathrm{~K}$, while the $5 d_{1}$ excitation band was not observed at $300 \mathrm{~K}$. These results show that the quenching process of the $\mathrm{CaAlSiN}_{3}: \mathrm{Eu}^{2+}$ phosphor is due to the thermal ionization. The moderate energy gap $(0.65 \mathrm{eV})$ between the lowest $5 d$ level and the conduction band in the vacuum referred binding energy diagram also supports the thermal ionization process.

\section{Acknowledgement}

This work was supported by JSPS KAKENHI (Grant numbers 16K05934 and 16H06441).

\section{References}

1 I. Akasaki, H. Amano and S. Nakamura, The Nobel Prize in Physics 2014. Nobel Media AB [Online] 2014, http://www.nobelprize.org/nobel_prizes/ph ysics/laureates/2014/ (accessed Augst 1, 2015).

2 K. Bando, K. Sakano, Y. Noguchi and Y. Shimizu, Journal of Light \& Visual Environment, 1998, 22, 2-4.

3 Y. Shimizu, K. Sakano, Y. Noguchi and T. Moriguchi, US Patent, 1999.

4 K. Uheda, N. Hirosaki and H. Yamamoto, physica status solidi (a), 2006, 203, 27122717.

5 K. Uheda, N. Hirosaki, Y. Yamamoto, A. Naito, T. Nakajima and H. Yamamoto, Electrochemical and Solid-State Letters, 2006, 9, H22-H25.

6 C. C. Lin and R.-S. Liu, The Journal of Physical Chemistry Letters, 2011, 2, 12681277.

7 Y.-T. Tsai, C.-Y. Chiang, W. Zhou, J.-F. Lee, H.-S. Sheu and R.-S. Liu, J. Am. Chem. Soc., 2015, 137, 8936-8939.

8 C. Struck and W. Fonger, Understanding Luminescence Spectra and Efficiency Using $W p$ and Related Functions, Springer Berlin Heidelberg, Berlin, Germany, 1991.

9 J. Zou, B. Yang, J. Li, S. Zhu, X. Qian and F. Wang, Ceramics International, 2016, 42 , 14956-14962.

10 S. Li, L. Wang, Q. Zhu, D. Tang, X. Liu, G. Cheng, L. Lu, T. Takeda, N. Hirosaki, Z. Huang and R.-J. Xie, J. Mater. Chem. C, 2016, 4, 11219-11230.

11 L. Chen, M. Fei, Z. Zhang, Y. Jiang, S. Chen, Y. Dong, Z. Sun, Z. Zhao, Y. Fu, J. He, C. Li and Z. Jiang, Chem. Mater., 2016 , 28, 5505-5515.

12 Z. Zhang, O. M. ten Kate, A. C. A. Delsing, M. J. H. Stevens, J. Zhao, P. H. L. Notten, P. Dorenbos and H. T. Hintzen, Journal of Materials Chemistry, 2012, 22, 2387123876.

13 P. Dorenbos, J. Phys.: Condens. Matter, 2005, 17, 8103-8111.

14 M. Mikami, ECS Journal of Solid State Science and Technology, 2013, 2, R3048R3058.

15 J. Ueda, R. Maki and S. Tanabe, Inorganic Chemistry, 2017, 56, 10353-10360.

16 J. Ueda, T. Nakanishi, Y. Katayama and S. Tanabe, physica status solidi (c), 2012, 9, 2322-2325.

17 J. Ueda, T. Shinoda and S. Tanabe, Optical Materials, 2015, 41, 84-89.

18 J. Ueda, P. Dorenbos, A. J. J. Bos, A. Meijerink and S. Tanabe, The Journal of 
Physical Chemistry C, 2015, 119, 2500325008.

19 J. Wang, H. Zhang, B. Lei, Z. Xia, H. Dong, Y. Liu, M. Zheng and Y. Xiao, J. Mater. Chem. C, 2015, 3, 4445-4451.

20 Z. Zhang, O. M. ten Kate, A. Delsing, E. van der Kolk, P. H. L. Notten, P. Dorenbos, J. Zhao and H. T. Hintzen, Journal of Materials Chemistry, 2012, 22, 9813-9820.

21 P. Dorenbos, J. Lumin., 2013, 135, 93-104.

22 P. Dorenbos, J. Lumin., 2005, 111, 89-104. 


\section{Graphical Abstract}

$<$ Title $>$ Thermal Quenching Mechanism of $\mathrm{CaAlSiN}_{3}: \mathrm{Eu}^{2+}$ Red Phosphor

<Authors' names> Jumpei Ueda, Setsuhisa Tanabe, Kohsei Takanashi, Takashi Takeda, Naoto Hirosaki

\section{$<$ Summary $>$}

$\mathrm{CaAlSiN}_{3}: \mathrm{Eu}^{2+}$ shows thermal quenching from around $400 \mathrm{~K}$. Based on the results of thermoluminescence glow curves and persistent luminescence excitation spectra, the electron charging process from the lowest $5 \mathrm{~d}$ excited state of Eu ${ }^{2+}$ to conduction band was observed at $450 \mathrm{~K}$. We conclude that the luminescence quenching of $\mathrm{CaAlSiN}_{3}: \mathrm{Eu}^{2+}$ at high temperatures is caused by the thermal ionization.
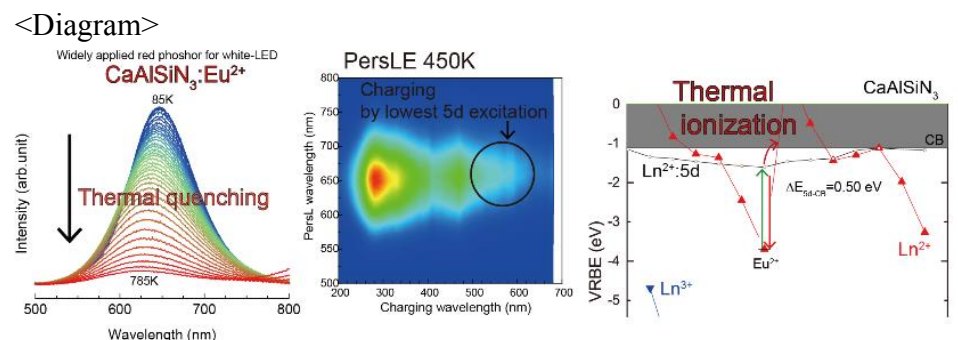